\title{
Originals
}

\section{The Pittsburgh Insulin-Dependent Diabetes Mellitus Registry: Seasonal Incidence}

\author{
H.A. Fishbein ${ }^{1}$, R. E. LaPorte ${ }^{2}$, T.J.Orchard ${ }^{2}$, A. L. Drash', L.H. Kuller ${ }^{2}$ and D. K. Wagener ${ }^{2}$ \\ ' Rhode Island Department of Health, Providence, Rhode Island, ${ }^{2}$ Department of Epidemiology, Graduate School of Public Health, \\ University of Pittsburgh and ${ }^{3}$ Department of Endocrinology, Children's Hospital of Pittsburgh, USA
}

\begin{abstract}
Summary. A total community (Allegheny County, Pennsylvania) Type 1 (insulin-dependent) diabetes mellitus registry was examined for evidence of seasonality at onset of the disease. No significant seasonal trend was found if all cases aged $<$ 20 years at onset $(n=901)$ were considered. However, a significant pattern emerged for the age groups 5-9 years and
\end{abstract}

10-14 years. Furthermore, sex differences were apparent in that males but not females demonstrated a seasonal pattern (fewer cases in the summer months).

Key words: Type 1 diabetes, epidemiology.
The onset of Type 1 (insulin-dependent) diabetes mellitus has been reported to follow a seasonal trend. As early as 1926, Adams [1] noted a pattern of lower incidence during the summer months. Other data from Europe [2-5], Chile [6] and the USA [7], all report a seasonal trend in the onset of diabetes with a higher number of cases during the autumn, spring and winter months with a reduced number of cases during the summertime.

Viral infections often follow seasonal patterns of occurrence. If there is a seasonal trend, this might suggest that a virus or other seasonal factors could be a precipitant of Type 1 diabetes. Viral agents, such as measles, mumps and Coxsackie that have a seasonal pattern, have been linked to the onset of Type 1 diabetes [8].

In addition to a possible viral aetiology, host characteristics influence susceptibility. Seasonality of Type 1 diabetes appears to be more predominant for males than females $[9,10]$. Also seasonality appears to vary with the age of onset $[9,11]$.

Many reports of seasonality have failed to use geographically defined population bases. Questions of incomplete ascertainment and biases in case reporting can also be raised in these studies. The present report provides a seasonal analysis of data from a populationbased Type 1 diabetes registry for Allegheny County, Pennsylvania, USA.

\section{Methods}

An ongoing registry of new onset cases of diabetes for Allegheny County, Pittsburgh, has been developed. Through retrospective record review, all cases diagnosed since 1965 have been identified [12].
Cases were identified by reviews of hospital, paediatric and outpatient diabetic clinic records. An extensive description of the registry has been described previously. The record reviews identified 973 new cases for the 12-year period 1965-1976. Seventy-two (7\%) of these cases did not have a confirmed month of diagnosis and therefore the reported analyses are on 901 cases.

For hospitalized cases, the date of diagnosis was taken as the date of discharge from the first admission for diabetes. The time of onset of symptoms could not be used as these data were not uniformly recorded and the date at discharge was more readily available than the admission date. Criteria for inclusion in the registry were: Allegheny County resident at time of diagnosis; age at diagnosis $<20$ years; discharged using insulin. For determining seasonal trend in onset, seasons were defined as spring (March, April, May), summer (June, July, August), autumn (September, October, November), and winter (December, January, February).

In the analyses we employed a significance test developed by Roger [13]. The test statistic ' $R$ ' is distributed approximately as a chisquare distribution with two degrees of freedom.

\section{Results}

\section{Yearly Seasonal Trends}

A 5-month moving average was employed to smooth the curves in order to graphically portray the seasonal trends. Figure 1 displays the moving average for the registry. There was no significant overall seasonal trend $(\mathrm{R}$ $=3.58, p>0.10$ ).

Table 1 presents the data by seasons for the 12 years. For 6 of the 12 years, the summer season had the fewest cases diagnosed. Additionally for 11 of the 12 vears, the summer season had the lowest or second lowest incidence of cases. Thus the seasonal trend was present, although relatively weak. 


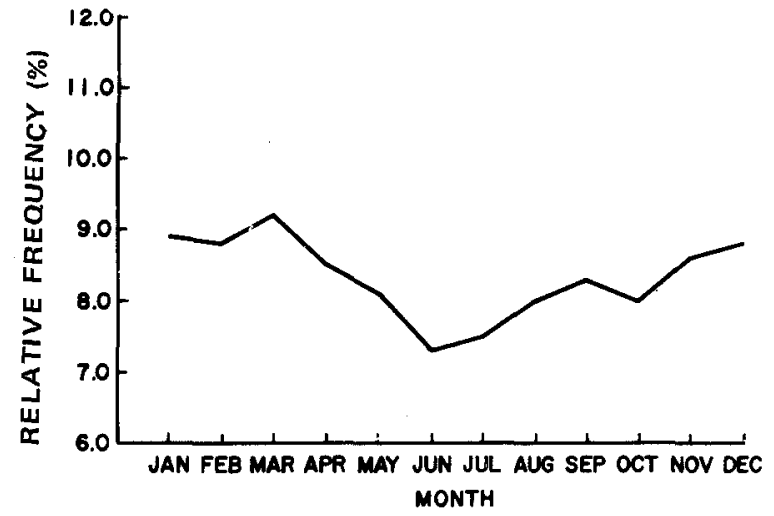

Fig. 1. Five month relative moving average: Total population

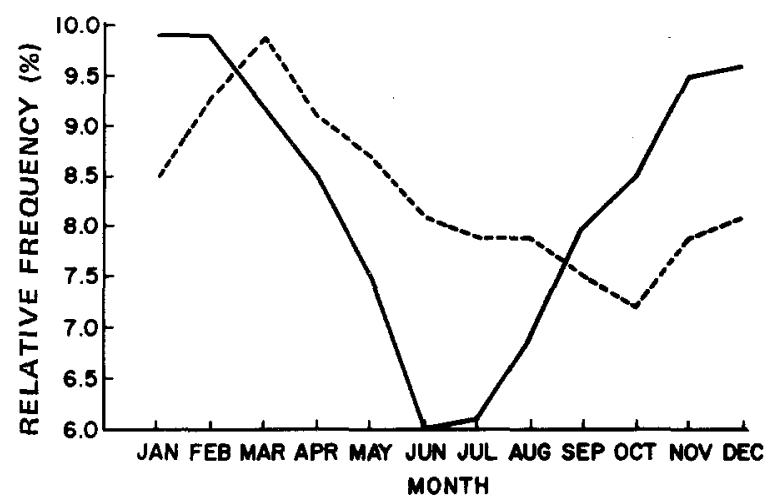

Fig. 2. Five month relative moving average: By age $-5-9$ years old; -.--10-14 years old

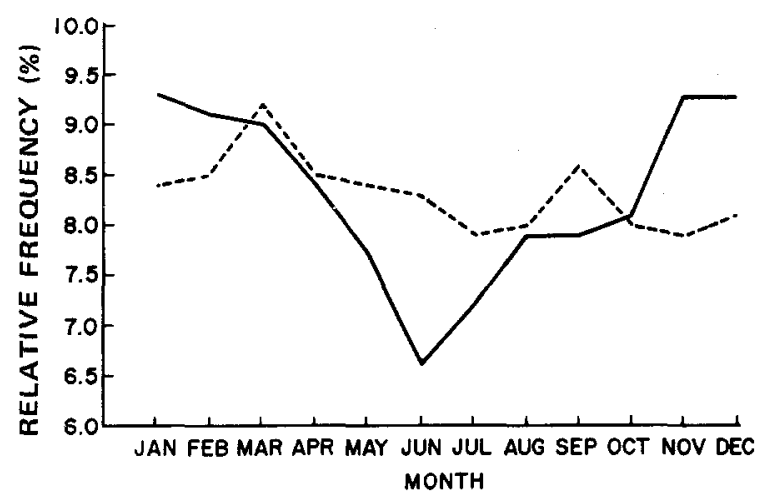

Fig. 3. Five month relative moving average: By sex - males; --.-- females

\section{Seasonality by Age at Onset}

There was little evidence for a seasonal effect in the $0-4$ year age group $(\mathrm{R}=0.89, p>0.20)$ or in the $15-19$ year age group $(R=1.73, p>2.0)$. A significant seasonal effect was found for the 5-9 year age group $(\mathrm{R}=6.88, p<0.05)$ and for the $10-14$ year age group $(\mathrm{R}=5.08, p<0.05$; Fig. 2$)$. The 5-9 year age group demonstrated a summer drop in cases, while the 10-14 year age group had the fewest cases diagnosed in the autumn.
Table 1. Seasonal onset by year of diagnosis in Allegheny County, Pennsylvania

\begin{tabular}{lccccc}
\hline \multirow{2}{*}{$\begin{array}{l}\text { Year of } \\
\text { diagnosis }\end{array}$} & \multicolumn{5}{l}{ Number of new cases by seasons } \\
\cline { 2 - 6 } & Winter & Spring & Summer & Autumn & Total \\
\hline 1965 & 11 & 13 & 12 & 20 & 56 \\
1966 & 22 & 16 & 17 & 16 & 71 \\
1967 & 17 & 13 & 10 & 14 & 54 \\
1968 & 17 & 26 & 15 & 21 & 79 \\
1969 & 21 & 29 & 12 & 23 & 85 \\
1970 & 21 & 22 & 15 & 25 & 83 \\
1971 & 20 & 25 & 20 & 18 & 83 \\
1972 & 17 & 19 & 15 & 21 & 72 \\
1973 & 17 & 19 & 18 & 22 & 76 \\
1974 & 29 & 22 & 16 & 15 & 82 \\
1975 & 25 & 11 & 26 & 25 & 87 \\
1976 & 15 & 22 & 15 & 21 & 73 \\
Total & 232 & 237 & 191 & 241 & 901 \\
\hline
\end{tabular}

Race

Overall the white population of cases $(n=832, \mathrm{R}=$ $3.44, p>0.10)$ and the black cases $(n=69, \mathrm{R}=0.42, p$ $>0.10$ ) exhibited no significant seasonal pattern of onset. It is important to recognize, however, that the sample size for blacks was small.

\section{Seasonality by Gender}

Males had a significant overall seasonality pattern $(\mathrm{R}=$ $4.75, p<0.05)$, but females did not $(\mathrm{R}=0.64, p>0.20$; Fig. 3). Fewer cases for males occurred during the summer months.

Sex and age-specific (yearly) seasonal trends were examined. Only three ages displayed significant seasonal patterns. The seasonal pattern for girls aged 8 years showed a marked reduction of cases in summer $(\mathrm{R}=$ $6.92, p<0.05$ ), while girls aged 12 years were diagnosed more often during the springtime followed by a summer decline $(\mathrm{R}=6.37, p<0.05)$. Boys aged 14 years exhibited a winter peak with a summer decline $(\mathrm{R}=6.25, p<0.05)$.

\section{Discussion}

For the 901 Type 1 diabetic cases with onset under age 20 years, there appeared to be a slight, but insignificant decrease in incidence during the summer. This is inconsistent with the results of a number of other studies reporting marked seasonality [1-7]. For many of these studies, inadequately defined populations were presented. Newly diagnosed Type 1 diabetic cases identified from single-centre institutions or isolated groups of institutions have incomplete data on which to base patterns of disease occurrence. Physician biases in referral patterns to particular institutions would further confound the data. Population-based registries like the one used in this report avoid these problems.

Inappropriate statistical tests have often been employed to test for seasonal trends. In the current re- 
search significant seasonality was found for only specific subsets of the registry.

Theories accounting for the larger numbers of cases detected in autumn and winter and the fewer cases in summer have included several possible explanations. Exposure to new infections on starting school may be a factor causing the increased number of cases diagnosed during the autumn for the 5-9 age group. However, this theory does not account for the sex difference noted in this and other studies nor for the autumn drop in cases for the 10-14 year old group.

Age-specific analyses revealed that 8 and 12-yearold girls and 14-year-old males exhibited a significant seasonal trend. Interestingly, the pattern of seasonality paralleled the peak ages of diabetes onset for males and females found in Pittsburgh [12], as well as other studies. The age of onset studies have indicated an early peak incidence (6-8 years) followed by a larger peak at later years (12-14 years). For the later peak there is a reported sex difference where females have a younger age at peak incidence than males. This may be due to an earlier puberty/growth spurt in females. Since the seasonality pattern directly parallels the peak age at onset results, both may be caused by a common factor or interaction of common factors.

Analyzing white and black cases separately resulted in no significant seasonality findings. The black sample size, however, was small and these data should be interpreted with caution.

The overall pattern of seasonality does not resemble the pattern seen with single virus infections that follow seasonal patterns. A striking feature of our data was the weak seasonal trend that changed little over the 12 years. If the onset was caused by an epidemic viral disease, then some years would show a strong seasonal pattern with large numbers of cases, whereas other years would exhibit little seasonality and few cases. Analyses indicated that none of the individual years displayed a significant seasonal pattern. Moreover, there was little variation in the number of new cases per year [12]. The model of a single virus precipitating Type 1 receives little support from our findings. If viruses play a role in precipitating diabetes, then it is likely that: 1) several viruses may be involved; or 2) host susceptibility plays a very critical role; or 3 ) the virus has uniform transmission throughout the year.

The primary difference in seasonality between the sexes (where males had a seasonal pattern and females did not) needs explanation. This may suggest that males are more susceptible to 'the agent' responsible for the seasonal pattern. If this were true, then one would expect a markedly higher incidence in males than females which has not been found [12]. An alternate explanation is that boys have a seasonal variation in exposure to the agents precipitating diabetes while girls have a more uniform exposure. Another explanation is that host characteristics related to susceptibility to diabetes may be seasonally related. For example, there is some suggestion of circannual variation in sex hormones [14].
Thus, the environmental agent may be constant but the susceptibility of the host varies according to sex and season. The results indicate that the seasonality effect varies as a function of host characteristics. What is clear is that a single hit model of a specific virus is unlikely to be responsible for the time of onset of diabetes unless it's pathogenicity varies considerably according to the age and sex of those infected.

Acknowledgements. We wish to thank Mrs. B.Schneider for her help. Research supported by a grant from the National Institutes of Heaith (R01 AM 24021).

\section{References}

1. Adams SF (1926) Seasonal variation in the onset of acute diabetes: Age and sex factors in 1,000 diabetic patients. Arch Intern Med 37: $861-864$

2. Christau B, Kromann $\mathrm{H}$, Anderson $\mathrm{O}$, Christy $\mathrm{M}$, Buschand $\mathrm{K}$, Arnung K, Kristensen I, Peitersen B, Steinrad J, Nerup J (1977) Incidence, seasonal and geographical patterns of juvenile-onset insulin-dependent diabetes mellitus in Denmark. Diabetologia 13: 281-284

3. Sterky G, Holmgren K, Gustavson KH, Larsson Y, Landmark KM, Nilsson KO, Samuelson G, Thalme B, Wall S (1978) The incidence of diabetes mellitus in Swedish children, 1970-1975. Acta Ped Scand 67: 139-143

4. Lestradet H, Besse J (1977) Prevalence and incidence of diabetes mellitus in children and adolescents (Part II, Proc). Acta Paediatr Belg 30: 123-127

5. Bloom A, Hayes TM, Gamble DR (1975) A register of newly diagnosed diabetic children. Br Med J 3: 580-583

6. Durruty P, Ruiz F, de los Rios MG (1979) Age at diagnosis and seasonal variation in the onset of insulin-dependent diabetes in Chile (Southern Hemisphere). Diabetologia 17: 357-360

7. Fleeger FM, Rogers KD, Drash AL, Rosenbloom AL, Travis LB, Court JM (1979) Age, sex and season of onset of juvenile diabetes in different geographic areas. Pediatrics 63: 374-379

8. Gamble DR (1980) The epidemiology of insulin-dependent diabetes with particular reference to the relationship of virus infection to its etiology. Epi Rev 2: 49-68.

9. Gray RS, Duncas LP, Clarke BF (1979) Seasonal onset of insulindependent diabetes in relation to sex and age at onset. Diabetologia 17:29-32

10. Cudworth AG, Gamble DR, White GBB, Lendrum R, Woodrow JC, Bloom A (1977) Aetiology of juvenile-onset diabetes: A prospective study. Lancet I: $385-388$

11. Gamble DR, Taylor KW (1969) Seasonal incidence of diabetes mellitus. Br Med J 3: 631-633

12. LaPorte RE, Fishbein HA, Drash AL, Kuller LH, Schneider BB, Orchard TJ, Wagener DR (1981) The Pittsburgh insulin-dependent diabetes mellitus (IDDM) registry: The incidence of insulindependent diabetes in Allegheny County, Pennsylvania (1965-1976). Diabetes 30: 279-284

13. Roger JH (1977) A significance test for cyclic trends in incidence data. Biometrika 64: 152-155

14. Smals AGH, Kloppenborg PWC, Benraad TJ (1976) Circannual cycle in plasma testosterone levels in men. $\mathbf{J}$ Clin Endocrinol Metab 42: 979-982

Received: 20 October 1981

and in revised form: 29 March 1982

Ronald E. LaPorte, Ph. D.

Department of Epidemiology

Graduate School of Public Health

University of Pittsburgh

Pittsburgh, PA 15261, USA 